\title{
Effects of Growth Conditions on AIN Layer Grown by Ga-Al Liquid Phase Epitaxy
}

\author{
Masayoshi Adachi, Ryuta Sekiya and Hiroyuki Fukuyama* \\ Institute of Multidisciplinary Research for Advanced Materials (IMRAM), Tohoku University, Sendai 980-8577, Japan
}

\begin{abstract}
We developed an original liquid phase epitaxy technique that uses Ga-Al solution to grow AlN on surface nitrided sapphire substrates. In this paper, effects of temperature, solution composition, and $\mathrm{N}_{2}$ gas flow rate on the growth of AlN layer were investigated. The AlN layer grown in the solution with higher $\mathrm{Al}$ content and higher growth temperature tended to dissolve into the solution, thus, the AlN layers exhibited inhomogeneous surface. The growth rate had a maximum at $60 \mathrm{~mol} \% \mathrm{Al}$ and at $1673 \mathrm{~K}$ for solution composition dependence and growth temperature dependence, respectively. On the other hand, the growth rate monotonically increased with increasing $\mathrm{N}_{2}$ gas flow rate. Based on these results, growth mechanism and rate-determined step of this liquid phase epitaxy process were discussed. [doi:10.2320/matertrans.M2016413]
\end{abstract}

(Received November 17, 2016; Accepted December 16, 2016; Published February 10, 2017)

Keywords: $\quad$ solution growth, aluminum nitride, epitaxial growth, gallium-aluminum flux

\section{Introduction}

AlGaN-based light-emitting diodes (LEDs) can be used as various light sources emitting from 3.4 to $6.0 \mathrm{eV}$ by controlling the ratio of AlN to GaN. Especially, AlGaN-based deep ultraviolet LEDs are expected as a substitute for mercury lamps for sterilization, water purification and curing. AlN has high ultraviolet transparency, high thermal conductivity, and small lattice mismatch with $\mathrm{AlGaN}$, therefore, $\mathrm{AlN}$ is one of the best substrate materials for the AlGaN-based LEDs. A number of groups fabricate bulk AlN single crystal using a sublimation method ${ }^{1-3)}$ and an alumina reduction method ${ }^{4-6)}$. Recently, Kumagai et al. ${ }^{7)}$ and Kangawa et al. ${ }^{8)}$ grew AlN single crystal by the hydride vapor phase epitaxy method and $\mathrm{Li}_{3} \mathrm{~N}$ solution growth method, respectively, using bulk AlN as a seed crystal fabricated by the sublimation method. Bockowski et al. fabricated AlN crystals from $\mathrm{Al}$ melt at high temperature up to $2000 \mathrm{~K}$ and high $\mathrm{N}_{2}$ pressure of order of $1 \mathrm{GPa}$ without seed crystal $^{9)}$. Their AIN crystals have very low threading dislocation density and impurity concentration. However, fabricating larger diameter AlN bulk crystal at a reasonable cost has not been achieved yet. Recently, P. Wu et al. reported the AlN growth method using vaporized $\mathrm{Al}$ and nitrogen gas as source materials ${ }^{10,11)}$. Some groups fabricated AlN by nitridation of metallic $\mathrm{Al}^{12-14)}$. These techniques are simple, however, fabrication of high quality AlN bulk crystal have not been reported. On the other hand, template growth of AlN single crystal on sapphire substrates has been also investigated by many researchers to obtain lager-diameter and lower-cost substrates. AlN has large lattice mismatch with sapphire, therefore, a few techniques to control the growth at the interface between AIN layer and sapphire substrate were reported $^{15-17)}$. In our group, we had developed a method for fabricating high-quality AlN thin films by nitriding sapphire under controlled conditions ${ }^{18,19)}$. Using the nitrided sapphire substrate as a template, DC-pulsed sputter deposition ${ }^{20,21)}$ and $\mathrm{RF}$ reactive sputtering techniques ${ }^{22,23)}$ have been investigated. Recently, authors have developed the Ga-Al liquid phase epitaxy (LPE) technique on the nitrided sapphire substrate, and have successfully grown $1.2-\mu \mathrm{m}$-thick AlN layer at $1573 \mathrm{~K}$ under normal pressure of $\mathrm{N}_{2}$ gas for $5 \mathrm{~h}^{24,25)}$. The full

*Corresponding author, E-mail: fukuyama@tagen.tohoku.ac.jp width at half maximum values of $\mathrm{X}$-ray rocking curves for (0002) and (10-12) were 90 and 392 arcsec, respectively ${ }^{26)}$. Moreover, we clarified that the polarity inversion of the AlN layer was caused by oxygen incorporation at the initial stage of the AlN solution growth ${ }^{27,28)}$, and oxygen plays an important role for the LPE growth.

In this study, the effects of solution composition and growth temperature on the AlN growth were studied to optimize the LPE process. Moreover, at the optimized temperature and solution composition, the effect of flow rate of $\mathrm{N}_{2}$ gas on the AlN growth was also studied. Based on these results, growth mechanism and rate-determined step of the LPE process were discussed.

\section{Experimental Method}

Experimental details and a schematic of the facility for the Ga-Al LPE technique were described in the previous paper ${ }^{24)}$. An alumina crucible containing the Ga-Al flux was set in a furnace at a homogeneous temperature zone. Inner diameter of the crucible was $50 \mathrm{~mm}$. The $\mathrm{Ga}-\mathrm{Al}$ flux was poured into the crucible to a height of $60-70 \mathrm{~mm}$. The nitrided c-plane sapphire substrates ${ }^{18,19)}(11 \mathrm{~mm} \times 10 \mathrm{~mm})$ were immersed into the $\mathrm{Ga}-\mathrm{Al}$ solution, and subsequently, $\mathrm{N}_{2}$ gas containing oxygen $\left(P_{\mathrm{O} 2}=10^{-6}\right.$ bar $)$ was injected into the solution directly through the alumina tube during the AIN growth. Inner diameter of the alumina tube was $4 \mathrm{~mm}$. The growth temperature and solution composition were varied from 1473 to $1773 \mathrm{~K}$ and from $\mathrm{Ga}-20 \mathrm{~mol} \% \mathrm{Al}$ to $\mathrm{Ga}-80 \mathrm{~mol} \% \mathrm{Al}$, respectively. Here, Ga- $x$ mol\% $\mathrm{Al}$ indicates a $\mathrm{Ga}-\mathrm{Al}$ alloy containing Al of $x$ mol\%. The LPE growth process was conducted at each growth temperature with a $\mathrm{N}_{2}$ gas flow rate of $20 \mathrm{sccm}$ for $5 \mathrm{~h}$. Finally, the $\mathrm{N}_{2}$ gas flow rate was varied from 10 to $100 \mathrm{sccm}$ at the optimized temperature and solution composition.

\section{Results}

\subsection{Effects of temperature and solution composition on AIN growth}

Figure 1 shows the surface morphologies of the AIN layers grown under each condition observed using a 3D laser microscope. The AlN layers with smooth surface grew uniformly 
on the substrates using $\mathrm{Ga}-20 \mathrm{~mol} \% \mathrm{Al}$ at $1573 \mathrm{~K}$, Ga$40 \mathrm{~mol} \% \mathrm{Al}$ at $1473 \mathrm{~K}$ and $1573 \mathrm{~K}$. Fringe patterns on these surface were caused by thickness distribution of the AIN layer. Details of the fringe patterns were explained in the previous paper ${ }^{24)}$. The AlN layer with rough surface grew on the substrate using Ga-40 mol\% Al at $1673 \mathrm{~K}$ because of the adhesion of three dimensional AlN crystal grains. Figure 2 shows a surface image of the AlN layer grown from Ga$40 \mathrm{~mol} \% \mathrm{Al}$ at $1673 \mathrm{~K}$ taken using a SEM. For other growth conditions, the AlN layers exhibits inhomogeneous surface caused by partial dissolution of AlN layer into the solution. The inhomogeneous surface did not indicate that the AlN grew by island growth mode. The AlN grew by film growth mode and dissolved into the solution simultaneously at difference position on the template, therefore, inhomogeneous surface appeared. The AlN layer tended to dissolve into the solution with higher $\mathrm{Al}$ content of solution and higher growth temperature.

Figure 3 shows (a) solution composition dependence at $1573 \mathrm{~K}$ and (b) temperature dependence of the growth rate of AlN layer. The growth rate was evaluated from the thickness of the AlN layers except for the dissolved area. All samples were grown for $5 \mathrm{~h}$. The growth rate has a maximum at $60 \mathrm{~mol} \% \mathrm{Al}$ as shown in Fig. 3(a). The growth rate has a maximum at $1673 \mathrm{~K}$ using $20 \mathrm{~mol} \% \mathrm{Al}$ solution as shown in Fig. 3(b). Thus, the growth rate exhibits non-monotonous be-

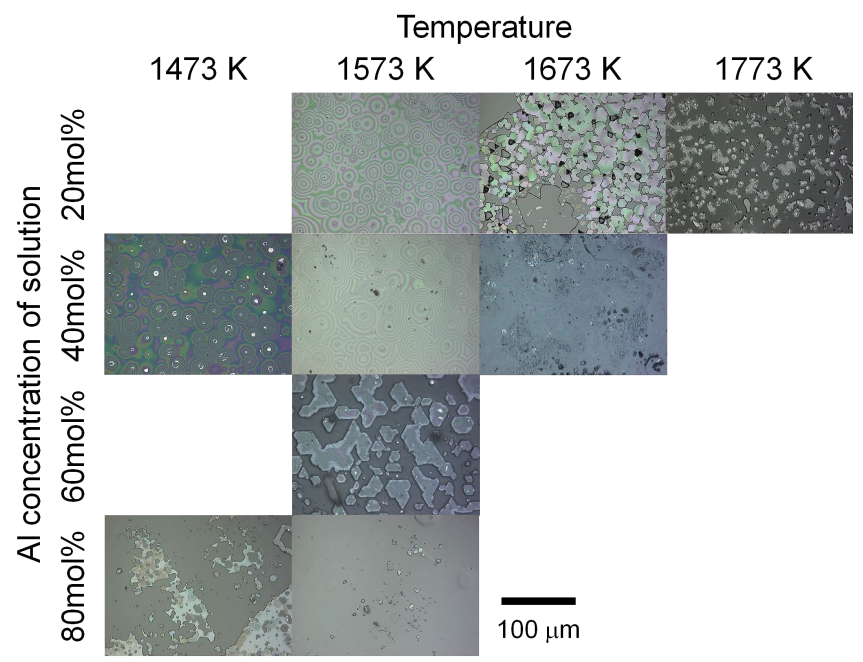

Fig. 1 Surface morphologies of the AlN layers grown under each condition observed using a 3D laser microscope.

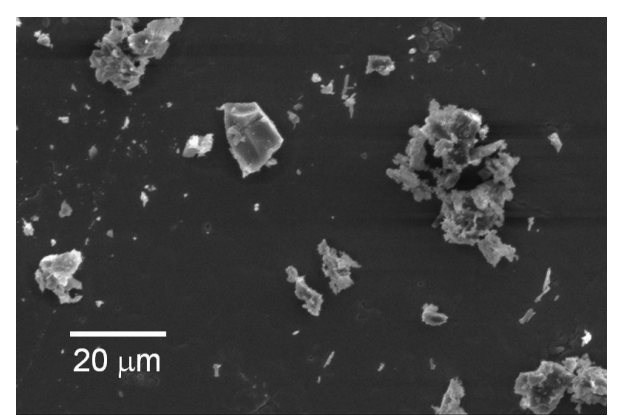

Fig. 2 Surface image of the AlN layer grown from $\mathrm{Ga}-40 \mathrm{~mol} \% \mathrm{Al}$ at $1673 \mathrm{~K}$ taken using a SEM. havior with growth temperature and solution composition.

\subsection{Effects of $\mathrm{N}_{2}$ gas flow rate on AIN growth}

From the result mentioned above, the AlN layer with smooth surface successfully grew from $\mathrm{Ga}-40 \mathrm{~mol} \% \mathrm{Al}$ at $1573 \mathrm{~K}$. With this condition, effect of the $\mathrm{N}_{2}$ gas flow rate on the AlN growth was studied. Figure 4 shows the surface morphologies of the AIN layers grown for $\mathrm{N}_{2}$ gas flow rates of (a) $10 \mathrm{sccm}$, (b) $20 \mathrm{sccm}$, (c) $50 \mathrm{sccm}$, and (d) $100 \mathrm{sccm}$. The

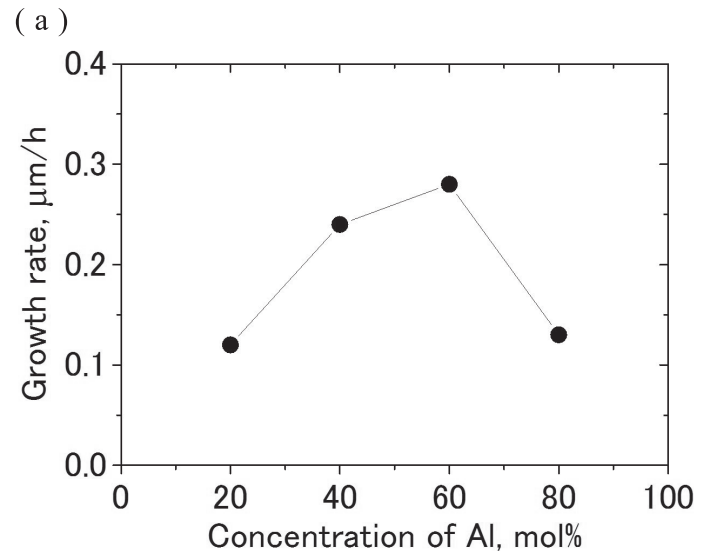

( b )

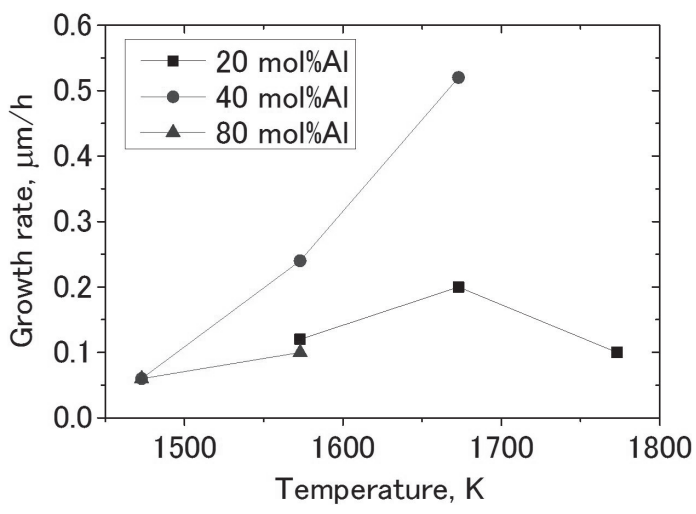

Fig. 3 (a) Solution composition dependence of the growth rate of AlN layer at $1573 \mathrm{~K}$. (b) temperature dependence of the growth rate of AlN layer.

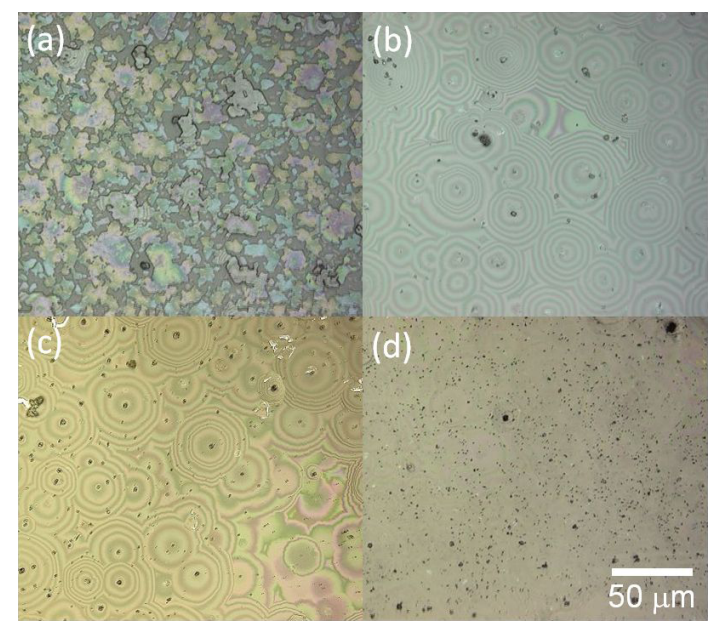

Fig. 4 (a) Surface morphologies of the grown AlN layers provided $\mathrm{N}_{2}$ gas at a flow rate of (a) $10 \mathrm{sccm}$, (b) $20 \mathrm{sccm}$, (c) $50 \mathrm{sccm}$ and (d) $100 \mathrm{sccm}$ observed using a laser microscope. 
AlN layers covered overall surface of the substrates except for $10 \mathrm{sccm}$. Figure 5 shows the effect of the $\mathrm{N}_{2}$ gas flow rate on the AlN growth. The growth rate monotonically increased with increasing $\mathrm{N}_{2}$ gas flow rate.

\section{Discussions}

As explained in the introduction, oxygen incorporation on the nitrided sapphire substrate at the initial stage of the LPE growth is necessary for polarity inversion and uniform growth $^{28)}$. Taking into account the oxygen incorporation, possible elementary steps of the LPE process are as follows, and the schematic of growth mechanism of the LPE process is shown in Fig. 6.

Step 1: Dissolution of nitrogen and oxygen gas into the solution

Step 2: Transport of dissolved nitrogen and oxygen atoms to the substrate

Step 3: Oxygen incorporation on the surface of substrate at the initial stage of growth

Step 4: AlN formation from the dissolved nitrogen and $\mathrm{Al}$ on the substrate

The dissolved nitrogen and oxygen in the solution are consumed by formation of $\mathrm{Al}_{2} \mathrm{O}_{3}$ and $\mathrm{AlN}$ as in a form of 3-dimensional nucleation in the solution using the higher $\mathrm{Al}$ content solution at higher temperature. This yields inhomogeneous growth of AlN layer as presented in Fig. 1, which results in the non-monotonous behavior in the growth rate as

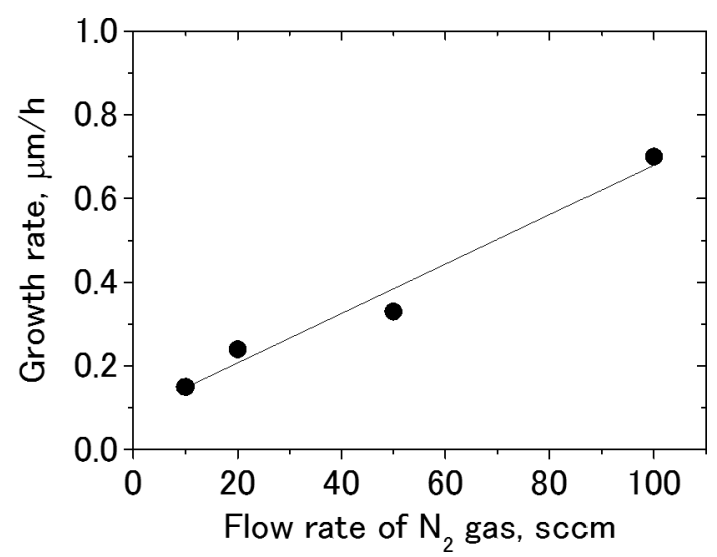

Fig. 5 Provided $\mathrm{N}_{2}$ gas flow rate dependence of growth rate the AlN layer.

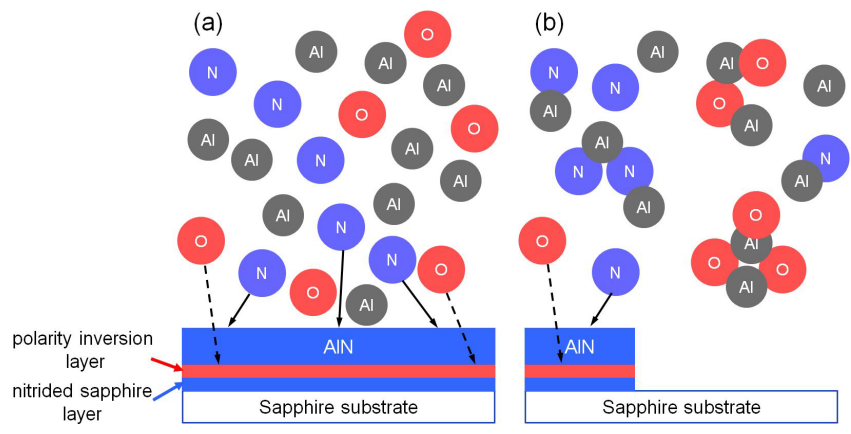

Fig. 6 Schematic of growth mechanism of the LPE process (a) in the lower $\mathrm{Al}$ content solution at lower temperature (b) in the higher Al content solution and/or at higher temperature. presented in Fig. 2. Thus, the growth process window is limited, and the optimized solution composition and temperature are $40 \mathrm{~mol} \% \mathrm{Al}$ and $1573 \mathrm{~K}$, respectively. Using the optimized condition, increasing $\mathrm{N}_{2}$ gas flow rate helps not only to supply nitrogen and oxygen, but also to agitate the solution. This leads to the increase in the growth rate as presented in Fig. 5. Therefore, we considered that rate-determining step under the optimized condition was elementary Step 1 or Step 2.

\section{Conclusions}

Effects of growth conditions such as temperature, solution composition and $\mathrm{N}_{2}$ gas flow rate on the LPE growth of AlN were studied to optimize the growth condition and to understand the growth mechanism. The optimized solution composition and growth temperature were $40 \mathrm{~mol} \% \mathrm{Al}$ and $1573 \mathrm{~K}$. The nitrogen and oxygen supply onto the nitrided sapphire substrates controls the growth rate under the optimized condition.

\section{Acknowledgments}

One of the authors (MA) is grateful for the financial support from JSPS KAKENHI Grant Number 26706013. This research was funded by the Cabinet Office, Government of Japan, through its Funding Program for Next Generation World-Leading Researchers (GR014).

\section{REFERENCES}

1) B.M. Epelbaum, M. Bickermann, S. Nagata, P. Heimann, O. Filip and A. Winnacker: J. Crys. Growth 305 (2007) 317.

2) Z.G. Herro, D. Zhuang, R. Schlesser and Z. Sitar: J. Crys. Growth 312 (2010) 2519.

3) D. Nakamura, A. Suzumura and K. Shigetoh: Appl. Phys. Lett. 106 (2015) 082108.

4) K. Hironaka, T. Nagashima, S. Ikeda, M. Azuma, K. Takada and H. Fukuyama: J. Crys. Growth 312 (2010) 2527.

5) Y. You, M. Kato, M. Ohtsuka and H. Fukuyama: J. Am. Ceram. Soc. 96 (2013) 3054.

6) H. Fukuyama, M. Kato, Y. You and M. Ohtsuka: Ceram. Int. 42 (2016) 5153.

7) Y. Kumagai, Y. Kubota, T. Nagashima, T. Kinoshita, R. Dalmau, R. Schlesser, B. Moody, J. Xie, H. Murakami, A. Koukitu and Z. Sitar: Appl. Phys. Express 5 (2012) 055504.

8) Y. Kangawa, R. Toki, T. Yayama, B.M. Epelbaum and K. Kakimoto: Appl. Phys. Express 4 (2011) 095501.

9) M. Boćkowski, M. Wróblewski, B. Łucznik and I. Grzegory: Mater. Sci. Semicond. Process. 4 (2001) 543.

10) P. Wu, M. Funato and Y. Kawakami: Sci. Rep. 5 (2015) 17405.

11) P. Wu, K. Kishimoto, M. Funato and Y. Kawakami: Cryst. Growth Des. 16 (2016) 6337.

12) W. Cheng, J. Jaw and C. Wang: Scr. Mater. 51 (2004) 1141.

13) J. Haibo, K. Chen, Z. Heping, S. Agathopoulos, O. Gabrichnaya and J.M.F. Ferreira: J. Crys. Growth 281 (2005) 639.

14) O. Takeda, K. Takagi, T. Handa, K. Katagiri, H. Zhu and Y. Sato: J. Mater. Res. 30 (2015) 635.

15) M. Imura, K. Nakano, T. Kitano, N. Fujimoto, G. Narita, N. Okada, K. Balakrishnan, M. Iwaya, S. Kamiyama, H. Amano, I. Akasaki, K. Shimoto, T. Noro, T. Takagi and A. Bandoh: Appl. Phys. Lett. 89 (2006) 221901.

16) H. Hirayama, T. Yatabe, N. Noguchi, T. Ohashi and N. Kamata: Appl. Phys. Lett. 91 (2007) 071901.

17) R. Miyagawa, S. Yang, H. Miyake, K. Hiramatsu, T. Kuwahara, M. 
Mitsuhara and N. Kuwano: Appl. Phys. Express 5 (2012) 025501.

18) H. Fukuyama, S. Kusunoki, A. Hakomori and K. Hiraga: J. Appl. Phys. 100 (2006) 024905.

19) H. Fukuyama, K. Nakamura, T. Aikawa, H. Kobatake, A. Hakomori, K. Takada and K. Hiraga: J. Appl. Phys. 107 (2010) 043502.

20) K. Ueno, E. Kishikawa, S. Inoue, J. Ohta, H. Fujioka, M. Oshima and H. Fukuyama: Phys. Status Solidi RRL 8 (2014) 256.

21) H. Takeuchi, M. Ohtsuka and H. Fukuyama: Phys. Status Solidi B 252 (2015) 1163.

22) T. Kumada, M. Ohtsuka, K. Takada and H. Fukuyama: Phys. Status Solidi C 8 (2011) 1520
23) T. Kumada, M. Ohtsuka, and H. Fukuyama: AIP Adv. 5 (2015) 017136.

24) M. Adachi, K. Maeda, A. Tanaka, H. Kobatake and H. Fukuyama: Phys. Status Solidi A 208 (2011) 1494.

25) M. Adachi, M. Sugiyama, A. Tanaka and H. Fukuyama: Mater. Trans. 53 (2012) 1295.

26) M. Adachi, K. Tsuda, M. Sugiyama, J. Iida, A. Tanaka and H. Fukuyama: Appl. Phys. Express 6 (2013) 091001.

27) M. Adachi, M. Takasugi, D. Morikawa, K. Tsuda, A. Tanaka and H. Fukuyama: Appl. Phys. Express 5 (2012) 101001.

28) M. Adachi, M. Takasugi, M. Sugiyama, J. Iida, A. Tanaka and H. Fukuyama: Phys. Status Solidi B 252 (2015) 743. 